\title{
Crystallization of Ba-ferrite/sapphire(001) Thin Films Studied by Real-Time Synchrotron X-ray Scattering
}

\author{
Tae Sik Cho* \\ Department of Materials Science and Engineering, Sangju National University, Sangju 742-711, Korea
}

(Received 10 June 2002)

\begin{abstract}
The crystallization of amorphous Ba-ferrite/sapphire(001) thin films was studied in real-time synchrotron $\mathrm{x}$-ray scattering experiments. In the sputter-grown amorphous films, we found the existence of epitaxial $\mathrm{Fe}_{3} \mathrm{O}_{4}$ interfacial crystallites $\left(50\right.$ - $\AA$-thick), well aligned $\left[0.03^{\circ}\right.$ full-width at half-maximum (FWHM)] to the sapphire [001] direction. The amorphous precursor was crystallized to epitaxial Ba-ferrite and $\alpha-\mathrm{Fe}_{2} \mathrm{O}_{3}$ grains in two steps; i) the nucleation of crystalline $\alpha-\mathrm{Fe}_{2} \mathrm{O}_{3}$ phase started at $300{ }^{\circ} \mathrm{C}$, together with the transformation of the $\mathrm{Fe}_{3} \mathrm{O}_{4}$ crystallites to the $\alpha-\mathrm{Fe}_{2} \mathrm{O}_{3}$ crystallites, ii) the nucleation of Ba-ferrite phase occurred at temperature above $600{ }^{\circ} \mathrm{C}$. In the crystallized films irrespective of the film thickness, the crystal domain size of the $\alpha-\mathrm{Fe}_{2} \mathrm{O}_{3}$ grains was about $250 \AA$ in the film plane, similar to that of the Ba-ferrite grains.
\end{abstract}

Key words : Ba-ferrite/sapphire(001) thin films, synchrotron x-ray scattering, crystallization, sputtering

\section{Introduction}

$\mathrm{BaO} \cdot 6 \mathrm{Fe}_{2} \mathrm{O}_{3}$ (Ba-ferrite) thin films are potentially important for high-density recording media due to their high anisotropy field, excellent chemical stability, and high mechanical hardness [1-3]. High crystallization temperature of Ba-ferrite phase, however, is a key obstacle in fabricating the recording media for practical applications $[3,4]$. Reducing the crystallization temperature of $\mathrm{Ba}$ ferrite phase is thus one of the important issues [3,5].

Crystalline Ba-ferrite films for recording media applications are usually obtained by a two-step process; deposition of an amorphous film at room temperature and crystallization of the film by post-annealing $[2,6]$. The local structure in the amorphous precursor of Ba-ferrite has been investigated [7]. The characteristics of the crystalline films obtained by post-annealing have also been extensively studied $[6,8]$. The crystallization behavior of the amorphous precursor of Ba-ferrite films during annealing, however, has not been systematically investigated.

In this article, we presented a real-time synchrotron $\mathrm{x}$ ray scattering study to elucidate the crystallization behavior of Ba-ferrite amorphous precursor films. Synchrotron $\mathrm{x}$ -

*Corresponding author: Tel: +82-54-530-5412, e-mail: tscho@ sangju.ac.kr ray scattering with very high flux and resolution is one of the best probes to study detailed phase transformations of amorphous thin films in in-situ during annealing. Our study revealed the detailed process of the crystallization of amorphous Ba-ferrite/sapphire(001) thin films during real-time annealing.

\section{Experimental Procedure}

\subsection{Sample preparation}

The Ba-ferrite amorphous precursor was grown on sapphire(001) substrates at room temperature by radio frequency ( $\mathrm{rf}$ ) magnetron sputtering of a stoichiometric Ba-ferrite target. As a carrier gas, a mixture of Ar-10\% $\mathrm{O}_{2}$ was used. The deposition rate of the film was about 4 $\AA / m i n$. The composition of amorphous precursor film, measured by Rutherford backscattering spectroscopy (RBS), was $\mathrm{Ba}_{0.8} \mathrm{Fe}_{12} \mathrm{O}_{20}$, somewhat $\mathrm{Ba}$ deficient due to the scattering loss $[6,9]$. The thickness of the amorphous precursor films was determined by $\mathrm{x}$-ray reflectivity measurement [10].

\subsection{Synchrotron $x$-ray scattering setup}

The synchrotron $x$-ray scattering experiments were performed at beamline 5C2 (K-JIST) at Pohang Light Source (PLS) in Korea. The incident $x$ rays were vertically focused by a mirror, and monochromatized to the 
wavelength of $1.447 \AA$ by a double bounce $\mathrm{Si}(111)$ monochromator. The monochromator also focused the $x$ rays in horizontal direction. Two pairs of slits in front of the detector provided an appropriate detector resolution. The experiments were carried out by measuring the conventional $\mathrm{x}$-ray powder diffraction profiles, the rocking curves, and the $\mathrm{x}$-ray reflectivity curves at several temperatures during annealing. The Ba-ferrite amorphous precursor film was annealed to $750{ }^{\circ} \mathrm{C}$ in air using a heating stage, which was set on a four-circle $\mathrm{x}$-ray diffractometer for the real-time $\mathrm{x}$-ray measurements. The temperature was raised step by step and kept constant during the x-ray measurements.

\section{Results and Discussion}

\subsection{Nanostructure of the as-deposited Ba-ferrite/sapphire} (001) thin films

We first carried out the powder diffraction measurement, for the as-deposited Ba-ferrite/sapphire(001) films (2000$\AA$-thick) grown at room temperature, by varying the momentum transfer $\mathbf{q}$ from 1.20 to $2.90 \AA^{-1}$ along the substrate normal direction. Figure 1 illustrates the powder diffraction pattern taken on the as-deposited films grown by the mixture of $\mathrm{Ar}-10 \% \mathrm{O}_{2}$. Considering that Ba-ferrite films grown by sputtering at room temperature are usually amorphous, it is remarkable that there exists one definite Bragg reflection. In Fig. 1, the Bragg reflection was peaked at $q_{z}=2.561 \AA^{-1}$ which corresponds to the $\mathrm{Fe}_{3} \mathrm{O}_{4}$ (222) reflection. The presence of the $\mathrm{Fe}_{3} \mathrm{O}_{4}$ phase is attributed to the Ba-deficiency in the films grown with the stoichiometric target $[6,9]$, as well as to the effect of the sapphire(001) substrate. Meanwhile, the absence of any

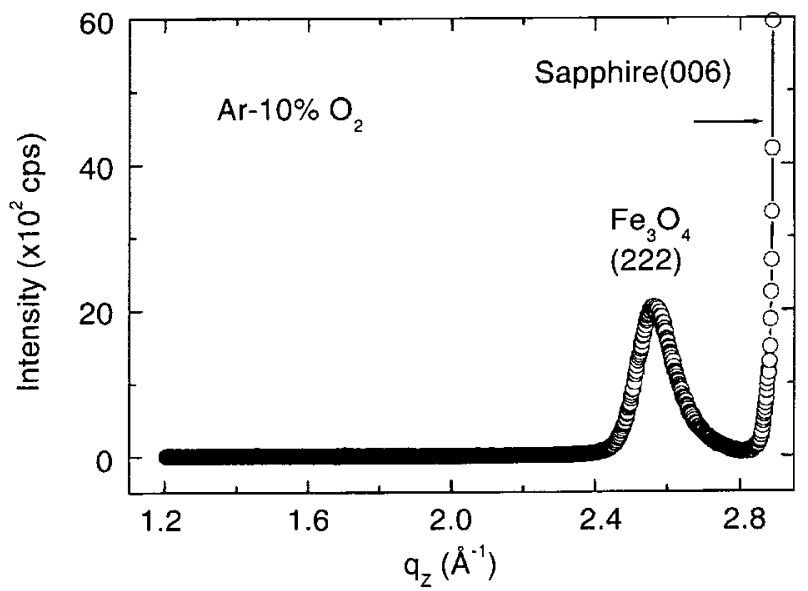

Fig. 1. X-ray powder diffraction profile taken on the as-deposited Ba-ferrite/sapphire(001) thin films grown by the mixture of $\mathrm{Ar}-10 \% \mathrm{O}_{2}$

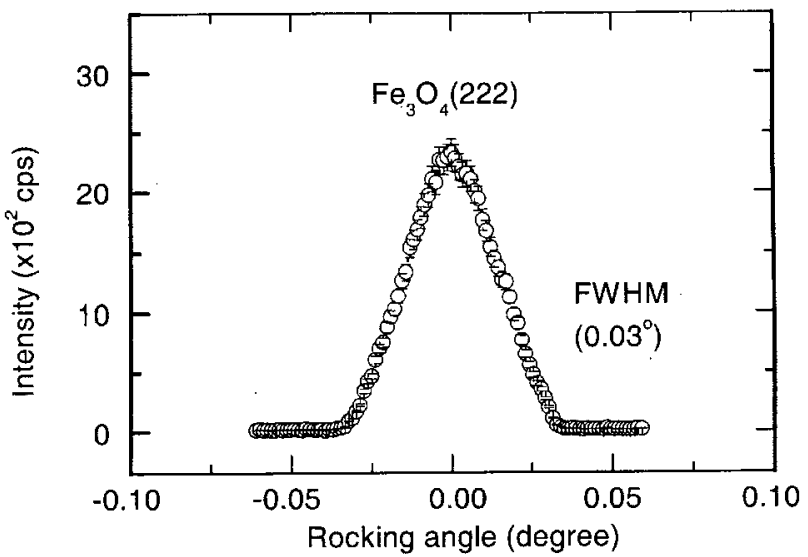

Fig. 2. Rocking curve of the $\mathrm{Fe}_{3} \mathrm{O}_{4}(222)$ Bragg reflection. The mosaic distribution was very sharp as $0.02^{\circ}$ FWHM in the reflection.

$\mathrm{Ba}$-ferrite reflection indicates that $\mathrm{Ba}$-ferrite was grown as amorphous phase.

We also noted that the full-width at half-maximum (FWHM) of the $\mathrm{Fe}_{3} \mathrm{O}_{4}$ (222) reflection was relatively very broad as $\Delta q_{z}=0.123 \AA^{-1}$ irrespective of the film thickness. The crystal domain size in the out-of-plane direction, which was estimated from the FWHM of the reflection using Scherrer's formular, was small as about $50 \AA$. Their mosaic distributions, however, was very sharp as $0.03^{\circ} \mathrm{FWHM}$, as illustrated in Fig. 2. From additional $\mathrm{Fe}_{3} \mathrm{O}_{4}$ (113) Bragg reflection measured on non-specular direction, we also found that the $\mathrm{Fe}_{3} \mathrm{O}_{4}$ crystallites were grown epitaxially on the sapphire(001) substrate (data not shown).

\subsection{Crystallization of Ba-ferrite/sapphire(001) thin films} during annealing

We discussed the crystallization behavior of the amorphous precursor of a $1500-\AA$-thick Ba-ferrite/sapphire (001) film grown by the mixture of $\mathrm{Ar}-10 \% \mathrm{O}_{2}$. Figure 3 showed a series of powder $\mathrm{x}$-ray diffraction profiles obtained during real-time annealing in air at several temperatures. It was remarkable that at room temperature there exists a definite Bragg reflection at $q_{z}=2.561 \AA^{-1}$, corresponding to the epitaxial $\mathrm{Fe}_{3} \mathrm{O}_{4}$ (222) interfacial crystallites. The $\mathrm{Fe}_{3} \mathrm{O}_{4}(222)$ crystallites were extremely well aligned to the substrate revealed by the sharp rocking curve of $0.03^{\circ}$ FWHM as shown in Fig. 4(a). Interestingly, the $\mathrm{q}_{\mathrm{z}}$ value of the $\mathrm{Fe}_{3} \mathrm{O}_{4}$ phase increased gradually with increasing the annealing temperature. With annealing temperature, the intensity of $\mathrm{Fe}_{3} \mathrm{O}_{4}$ (222) peak gradually decreased and disappeared mostly as the annealing temperature approached to $700{ }^{\circ} \mathrm{C}$.

In the meanwhile, the $\alpha-\mathrm{Fe}_{2} \mathrm{O}_{3}$ phase was nucleated in 


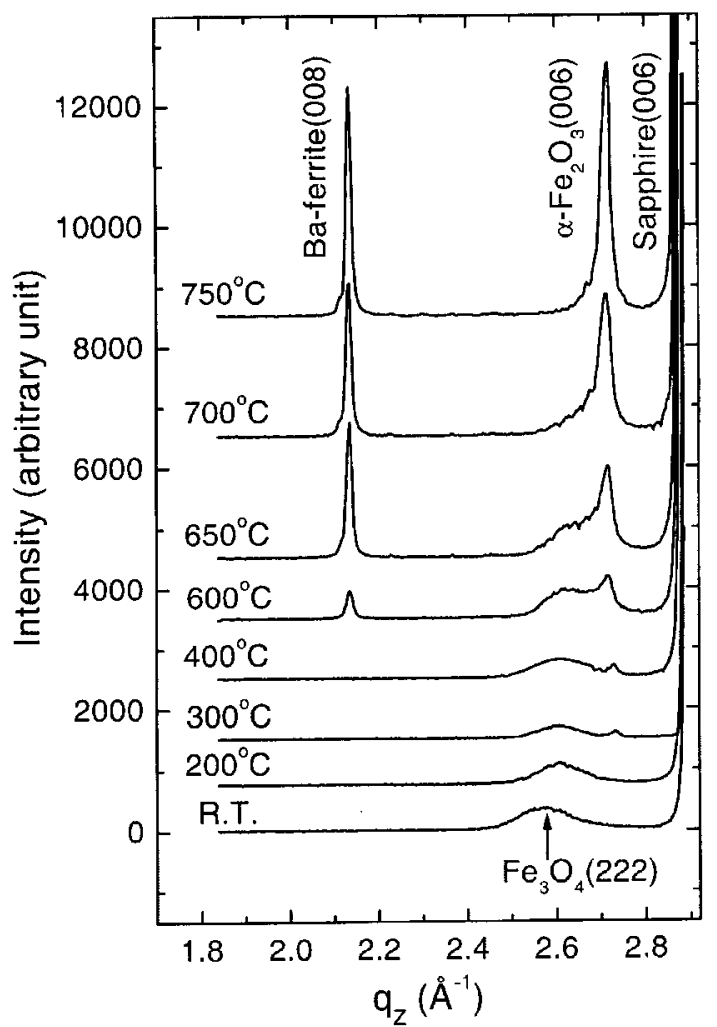

Fig. 3. $X$-ray powder diffraction profiles of a 1500 - $\AA$-thick amorphous precursor of $\mathrm{Ba}-\mathrm{ferrite} / \mathrm{sapphire(001)}$ film measured during real-time annealing at several temperatures in air.

the amorphous precursor at $300{ }^{\circ} \mathrm{C}$, as revealed by the appearance of the $\alpha-\mathrm{Fe}_{2} \mathrm{O}_{3}(006)$ Bragg reflection at $q_{z}=$ $2.75 \AA^{-1}$ in Fig. 3. The $\alpha-\mathrm{Fe}_{2} \mathrm{O}_{3}$ grains nucleated with the $<001>$ preferred orientation in the amorphous precursor, although they were relatively less aligned to the substrate as revealed in the rocking curve shown in Fig. 4(b), compared to the $\mathrm{Fe}_{3} \mathrm{O}_{4}$ crystallites. Interestingly, the rocking curve of the $\alpha-\mathrm{Fe}_{2} \mathrm{O}_{3}(006)$ reflection at $600{ }^{\circ} \mathrm{C}$ and $700{ }^{\circ} \mathrm{C}$ consisted of a sharp and a broad components as shown in Figs. 4(c) and 4(d). The mosaicity of the well-aligned a$\mathrm{Fe}_{2} \mathrm{O}_{3}(006)$ grains was $0.05^{\circ} \mathrm{FWHM}$, nearly the same as that of $\mathrm{Fe}_{3} \mathrm{O}_{4}$ interfacial crystallites. Since the $\mathrm{Fe}_{3} \mathrm{O}_{4}$ phase started to disappear at $600{ }^{\circ} \mathrm{C}$, we confirm that the wellaligned $\alpha-\mathrm{Fe}_{2} \mathrm{O}_{3}$ grains were transformed from the wellaligned $\mathrm{Fe}_{3} \mathrm{O}_{4}$ crystallites.

Crystalline Ba-ferrite phase started to nucleate at high temperature of $600{ }^{\circ} \mathrm{C}$ and grew continuously up to 750 ${ }^{\circ} \mathrm{C}$, the highest annealing temperature used in this experiment. The rocking curve of the Ba-ferrite $(008)$ was also relatively broad. The Ba-ferrite was also nucleated with the $<001>$ preferred orientation with the mosaic distribution of about one degree as shown in Fig. 4(c). We also confirmed that both the Ba-ferrite and the $\alpha-\mathrm{Fe}_{2} \mathrm{O}_{3}$

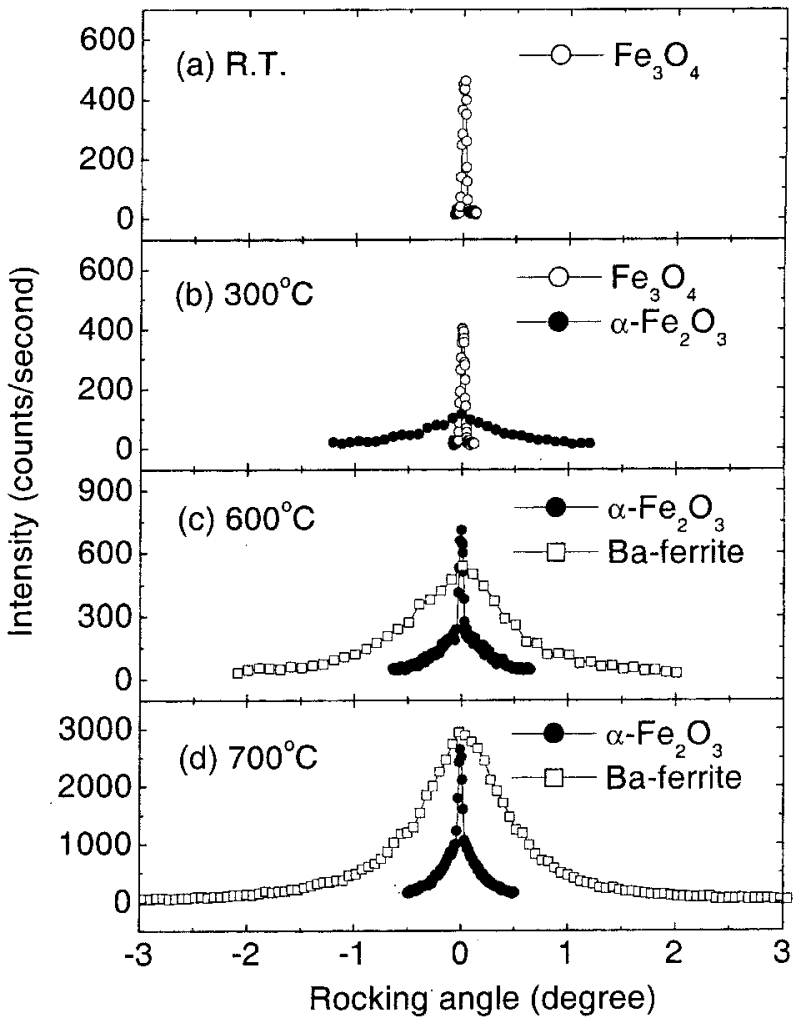

Fig. 4. Rocking curves of the $\mathrm{Fe}_{3} \mathrm{O}_{4}$ (222), the $\alpha-\mathrm{Fe}_{2} \mathrm{O}_{3}(006)$, and the Ba-ferrite (008) Bragg reflections measured during real-time annealing at several temperatures.

phases were grown epitaxially to the substrate by investigating Bragg reflections in non-specular directions (data not shown). The epitaxial relationship was summarized as $\alpha-\mathrm{Fe}_{2} \mathrm{O}_{3}(006)$ [Ba-ferrite $\left.(00 l)\right] / /$ sapphire $(00 l), \alpha-\mathrm{Fe}_{2} \mathrm{O}_{3}$ $<100>/ /$ sapphire $<100>$, and Ba-ferrite $<100>/ /$ sapphire $<110>$ [11].

\subsection{Nanostructure of the crystallized Ba-ferrite/sapphire (001) thin films}

Murdoch has estimated that recording at densities of 10 Gbit/in ${ }^{2}$ will require $100 \AA$ grains that are magnetically decoupled from neighboring grains [12]. However, the grain size is usually greater than the magnetic domain size, probably due to defects within grains. Also, the crystal domain size is directly related with defects. We estimated the crystal domain size of the $\alpha-\mathrm{Fe}_{2} \mathrm{O}_{3}$ and the Ba-ferrite grains in the film normal direction and in the film plane direction by the FWHM of the scattering profile. Figure 5 showed that the crystal domain size of the $\alpha-\mathrm{Fe}_{2} \mathrm{O}_{3}$ grains were very similar to those of Ba-ferrite grains. In the film plane, the $\alpha-\mathrm{Fe}_{2} \mathrm{O}_{3}$ and the Ba-ferrite grains have comparable crystal domain size of about 250 irrespective of the film thickness, as illustrated in Fig. 


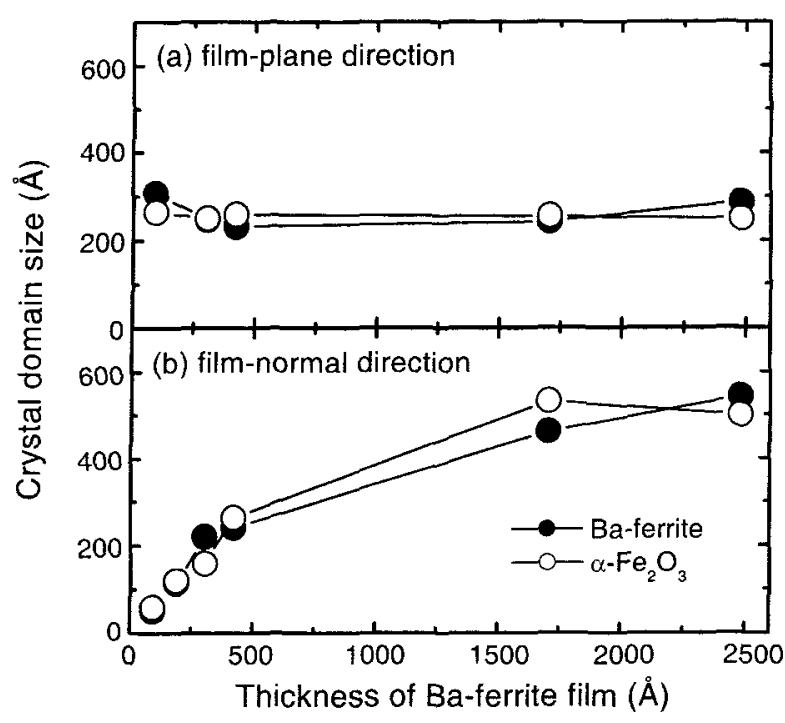

Fig. 5. Crystal domain sizes of the $\alpha-\mathrm{Fe}_{2} \mathrm{O}_{3}$ and the Ba-ferrite grains in (a) the film-plane direction and in (b) the film-normal direction as a function of film thickness. The crystal domain sizes of the $\alpha-\mathrm{Fe}_{2} \mathrm{O}_{3}$ grains were very similar to those of $\mathrm{Ba}$ ferrite grains.

5(a). We also observed, in the film normal direction, that the crystal domain sizes were very similar each other in $\alpha-\mathrm{Fe}_{2} \mathrm{O}_{3}$ and Ba-ferrite grains, as shown in Fig. 5(b). As the film thickness increased to $2500 \AA$, the out-of-plane crystal domain sizes increased to about $500 \AA$ in both phases. We reported that, in films thicker than $1000 \AA$, acicular grains keeping the magnetically easy $c$-axis parallel to the film plane were grown on top of the perpendicular grains keeping the c-axis normal to the film plane [13]. The very similar crystal domain sizes of the Ba-ferrite and the $\alpha-\mathrm{Fe}_{2} \mathrm{O}_{3}$ grains also related that the crystalline $\mathrm{Ba}$ ferrite phase was formed by solid phase transformation of the intermediate $\alpha-\mathrm{Fe}_{2} \mathrm{O}_{3}$ phase [14].

\section{Conclusions}

We revealed the detailed process of the crystallization of amorphous Ba-ferrite/sapphire(001) thin films using real-time synchrotron $x$-ray scattering experiments. In the sputter-grown amorphous films, we found the existence of epitaxial $\mathrm{Fe}_{3} \mathrm{O}_{4}$ interfacial crystallites (50- $\AA$-thick), well aligned $\left[0.03^{\circ}\right.$ full-width at half-maximum (FWHM)] to the sapphire[001] direction. The amorphous precursor was epitaxially crystallized to the Ba-ferrite and the $\alpha$ $\mathrm{Fe}_{2} \mathrm{O}_{3}$ grains in two steps; i) the nucleation of crystalline $\alpha-\mathrm{Fe}_{2} \mathrm{O}_{3}$ phase started at $300{ }^{\circ} \mathrm{C}$, together with the transformation of the $\mathrm{Fe}_{3} \mathrm{O}_{4}$ crystallites to the $\alpha-\mathrm{Fe}_{2} \mathrm{O}_{3}$ crystallites, ii) the nucleation of Ba-ferrite phase occurred at temperature above $600{ }^{\circ} \mathrm{C}$. The crystal domain size of the $\alpha-\mathrm{Fe}_{2} \mathrm{O}_{3}$ grains was about $250 \AA$ in the film plane, similar to that of the Ba-ferrite grains. The epitaxial relationship was summarized as $\alpha-\mathrm{Fe}_{2} \mathrm{O}_{3}(006)$ [Ba-ferrite $(001)] / /$ sapphire $(001), \quad \alpha-\mathrm{Fe}_{2} \mathrm{O}_{3}<100>/ /$ sapphire $\left.<100\right\rangle$, and Ba-ferrite $<100>/ /$ sapphire $<110>$. We confirmed that the existence of the antiferromagnetic $\alpha-\mathrm{Fe}_{2} \mathrm{O}_{3}$ grains greatly degraded magnetic properties of the $\mathrm{Ba}$-ferrite films for high-density recording media.

\section{Acknowledgments}

This study was supported by Sangju National University grant. This work was also supported by grant No. (R052002-000-01186-0) from the Basic Research Program of the KOSEF.

\section{References}

[1] T. L. Hylton, M. A. Parker, M. Ullah, K. R. Coffey, R. Umphress, and J. K. Howard, J. Appl. Phys. 75, 5960 (1994).

[2] X. Sui and M. H. Kryder, Appl. Phys. Lett. 63, 1582 (1993).

[3] A. Morisako, X. Liu, M. Matsumoto, and M. Naoe, J. Appl. Phys. 81, 4374 (1997).

[4] P. C. Dorsey, S. B. Qadri, K. S. Grabowski, D. L. Knies, P. Lubitz, D. B. Chrisey, and J. S. Horwitz, Appl. Phys. Lett. 70, 1173 (1997).

[5] A. Morisako, H. Nakanishi, M. Matsumoto, and M. Naoe, J. Appl. Phys. 75, 5969 (1994).

[6] T. L. Hylton, M. A. Parker, and J. K. Howard, Appl. Phys. Lett. 61, 867 (1992).

[7] J. E. Snyder, V. G. Harris, N. C. Koon, X. Sui, and M. H. Kryder, Phys. Rev. Lett. 77, 3383 (1996).

[8] A. Morisako, M. Matsumoto, and M. Naoe, IEEE Trans. Magn. 32, 3819 (1996).

[9] E. Suzuki, Y. Hoshi, and M. Naoe, J. Appl. Phys. 83, 6250 (1998).

[10] T. S. Cho, S. J. Doh, J. H. Je, and D. Y. Noh, Jpn. J. Appl. Phys. 38-1, 444 (1999).

[11] T. S. Cho, S. J. Doh, J. H. Je, and D. Y. Noh, Appl. Phys. Lett. 74, 2050 (1999).

[12] E. S. Murdoch, IEEE Trans. Magn. 28, 3078 (1992).

[13] T. S. Cho, S. J. Doh, J. H. Je, and D. Y. Noh, J. Appl. Phys. 86, 1958 (1999).

[14] T. S. Cho, J. H. Je, and D. Y. Noh, Appl. Phys. Lett. 76, 303 (2000) 